\title{
Strengthening of RC Beams with Solid Steel Plates
}

\author{
By Eray Ozbek \\ Meryem Bocek ${ }^{*}$ \\ Sabahattin Aykac ${ }^{+}$
}

Strengthening of $R C$ beams by bonding steel plates to the bottom face of the beams against flexure is a commonly used method. However, significant ductility problems have been encountered in the studies carried out so far. In this study a simple and applicable end connection has been developed to achieve a satisfied ductility level in addition to the strength. A total of four full scale RC beams, one of them a reference beam, were prepared and tested. Three beams were strengthened against flexure. Despite the increase in the strength about two-andhalf-times, it was found that the behaviour of specimens was still quite ductile.

Keywords: Epoxy-bonded plate, Flexure, Shear, Structural strengthening.

\section{Introduction}

Strengthening of $\mathrm{RC}$ beams is usually needed due to various reasons, including the changes in the use of the structure and design and construction faults. Several methods have been proposed and implemented in the literature for this purpose. Addition of a new reinforced concrete (RC) layer (Aykac, 2001) or gluing FRP laminates (Moon et al., 2007; Yang et al., 2009; Mukherjee and Rai, 2009; Li et al., 2006, 2008; Bank and Arora, 2007; Toutanji et al., 2006; Anania et al., 2005; Ashour et al., 2004; Ali et al., 2001) to the soffit of the beam are among the investigated beam strengthening methods. Strengthening the beam with an additional $\mathrm{RC}$ layer proved to be efficient in improving the flexural behavior. Nonetheless, this method is quite cumbersome to apply particularly in real structures, where several beams need to be strengthened. Although FRP composites are efficient strengthening materials owing to their several superiorities, such as high strength and good bonding quality with concrete, their brittle stress-strain behavior limits the overall ductility of the beam. Furthermore, FRP composites are more costly compared to other strengthening materials (steel, $\mathrm{RC}$, shotcrete, etc.) and their fire resistance is low, which can be a cause of concern in structures prone to fire. Owing to the relatively lower prices and ductile stress-strain properties of steel, bonding steel plates to the tension faces of the beams is a significant alternative to the available strengthening methods (Tankut and Arslan, 1992; Arslan, 1991; Gülenler, 1977; Raoof et al., 2000; Uysal, 2006; Karahan, 2008; Kayar, 2008; Su and Zhu, 2005).

\footnotetext{
* Research Assistant, Gazi University, Turkey.

* Research Assistant, Gazi University, Turkey.

${ }^{+}$Associate Professor, Gazi University, Turkey.
} 
Despite their several advantages, the externally-bonded steel plates might limit the ductility of a strengthened beam. A plated beam is liable to sudden brittle failure particularly if the connections at the plate curtailment are not capable of transmitting the loads between the plate and the beam. The present study is devoted to devising new connection details to overcome the load transmission problems at plate curtailment to enhance the overall ductility of the plated beam. A simple and easy-to-apply connection detail developed through a series of tests is presented. The test results of three plated beams with this connection detail are also presented in this paper together with the test results of a reference monolithic beam for comparison. As well as its contribution to the load capacity of the beam, the present connection detail also provided the beams with a ductile flexural behavior.

The use of a compression plate in addition to the soffit plate and the bonding of the soffit plate to the beam with or without epoxy were the two test parameters investigated in the present study. All of the specimens had identical end connection details and identical strengthening plate cross-section. The crosssection of the soffit plate was chosen in such a way that the total reinforcement ratio of the strengthened beam was equal to the maximum tension reinforcement ratio (0.02) allowed by the Turkish (TS 500) (2000) Code.

\section{Experimental Program}

\section{Specimens and Strengthening Methods}

Real-scale T-beams with a width of $200 \mathrm{~mm}$, an overall height of $500 \mathrm{~mm}$ and a total length of $4500 \mathrm{~mm}$ were tested in the present study. The flange was $100 \mathrm{~mm}$ in thickness and $400 \mathrm{~mm}$ in width. All specimens, including the reference one, were reinforced with $3 \varnothing 14$ tension reinforcing bars and $2 \varnothing 10$ and $4 \varnothing 8$ compression reinforcing bars (Figure 1). The slab contained $\varnothing 8 / 300$ and $\varnothing 8 / 150$ bottom and top reinforcement, respectively. All reinforcing bars were of Grade 420. The strengthening details of the specimens are given in Table 1. All of the specimens were originally weak in bending to examine the influence of the strengthening applications on the flexural behavior of RC beams. In specimens S2 and S3, compression plates were used as well as the tension (soffit) plate. Different from S3, these plates were not epoxy-bonded to the beam in S2 (Figure 2). In all specimens, the tension plates were connected to the beam with the help of side plates and the side plates were fastened to the beam with $7 \mathrm{M} 20$ anchor bolts, as shown in Figure 2. The bolts extended an anchorage depth about half of the beam depth into the beam. The number of bolts was chosen so that the shear strength between the side plates and the beam could allow the soffit plate to reach its tension capacity with no premature failure at the plate curtailment. The bolts were not post-tensioned.

The compression plates in S2 and S3 were $400 \mathrm{~mm}$ wide, $6 \mathrm{~mm}$ thick and $1700 \mathrm{~mm}$ long. The length of these plates was chosen in such a way that these plates extend about $80 \%$ of the distance between the zero-moment (inflection) points in the span. The compression plates were fastened to the bottom side of the 
flange with the help of M12 bolts, spaced at $200 \mathrm{~mm}$ (Figure 2) to prevent the buckling of these plates in the progressive stages of loading. The material tests indicated that the average concrete strength was about $16 \mathrm{MPa}$ in all specimens and the reinforcement had average yield and ultimate strength values of 450 and $620 \mathrm{MPa}$, respectively. The yield and ultimate tensile strengths of the soffit and compression plates were measured as $280 \mathrm{MPa}$.

\section{Test Setup}

Tests were conducted in a steel test frame strengthened with diagonal bars (Figure 3). The beams were simply supported and subjected to two-point loading. The load was applied with the help of a rigid steel spreader beam and a hydraulic jack. The distance between the two loading points was chosen in a way that the moment diagram of the beam matches the moment curvature diagram in the case of uniformly distributed loading.

Figure 1. The Reference Beam

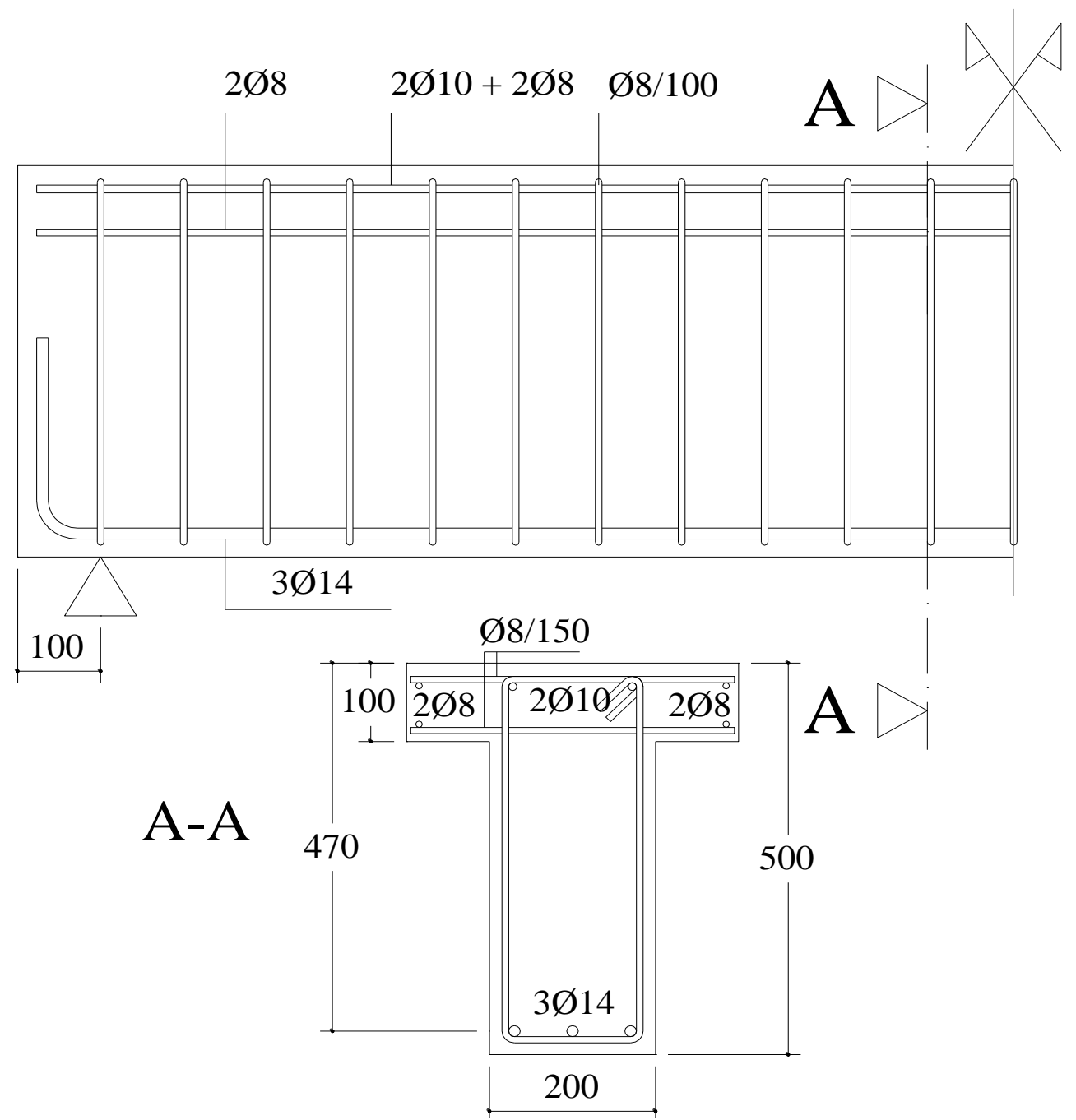


Table 1. Properties of Test Specimens

\begin{tabular}{|c|c|c|}
\hline Specimen & Plate thickness & Strengthening Type \\
\hline RB & --- & --- \\
\hline S1 & $6 \mathrm{~mm}$ & Bottom plate with epoxy \\
\hline S2 & $6 \mathrm{~mm}$ & Upper and bottom plates without epoxy \\
\hline S3 & $6 \mathrm{~mm}$ & Upper and bottom plates with epoxy \\
\hline
\end{tabular}

Displacement transducers (LVDT) were placed underneath the supports, at midspan and at the loading points to measure the vertical displacements at these points, as shown in Figure 3. Additional LVDT's were also used around midspan of the beam to determine the curvature.

Figure 2. Specimen $S 3$

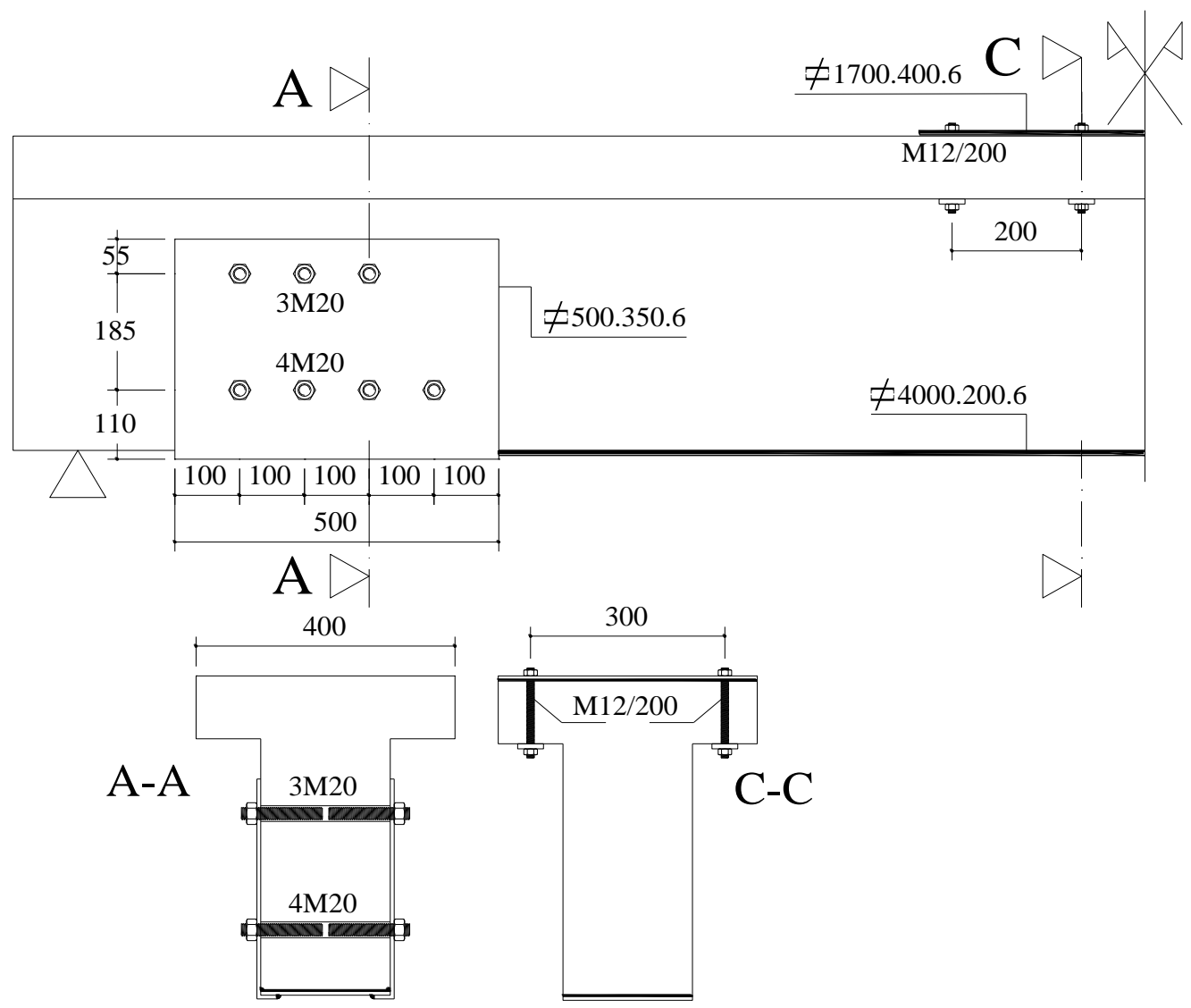

\section{Evaluation of the Test Results}

Load-deflection graphs of the specimens are shown in Figure 4 and the test results are summarized in Table 2. Yielding deflection of each specimen corresponds to the deflection value at the intersection of the extensions of the initial linear and plastic portions of the curve. Ductility ratio of each specimen corresponds to the ratio of the ultimate deflection (deflection at $85 \%$ of the 
ultimate load at the descending portion of the load-deflection curve) to the yielding deflection. The unloading and reloading portions of the curves in Figure 4 were caused by the adjustments of the test setup during the test due to the inadequate stroke of the hydraulic jack.

Figure 3. Test Setup

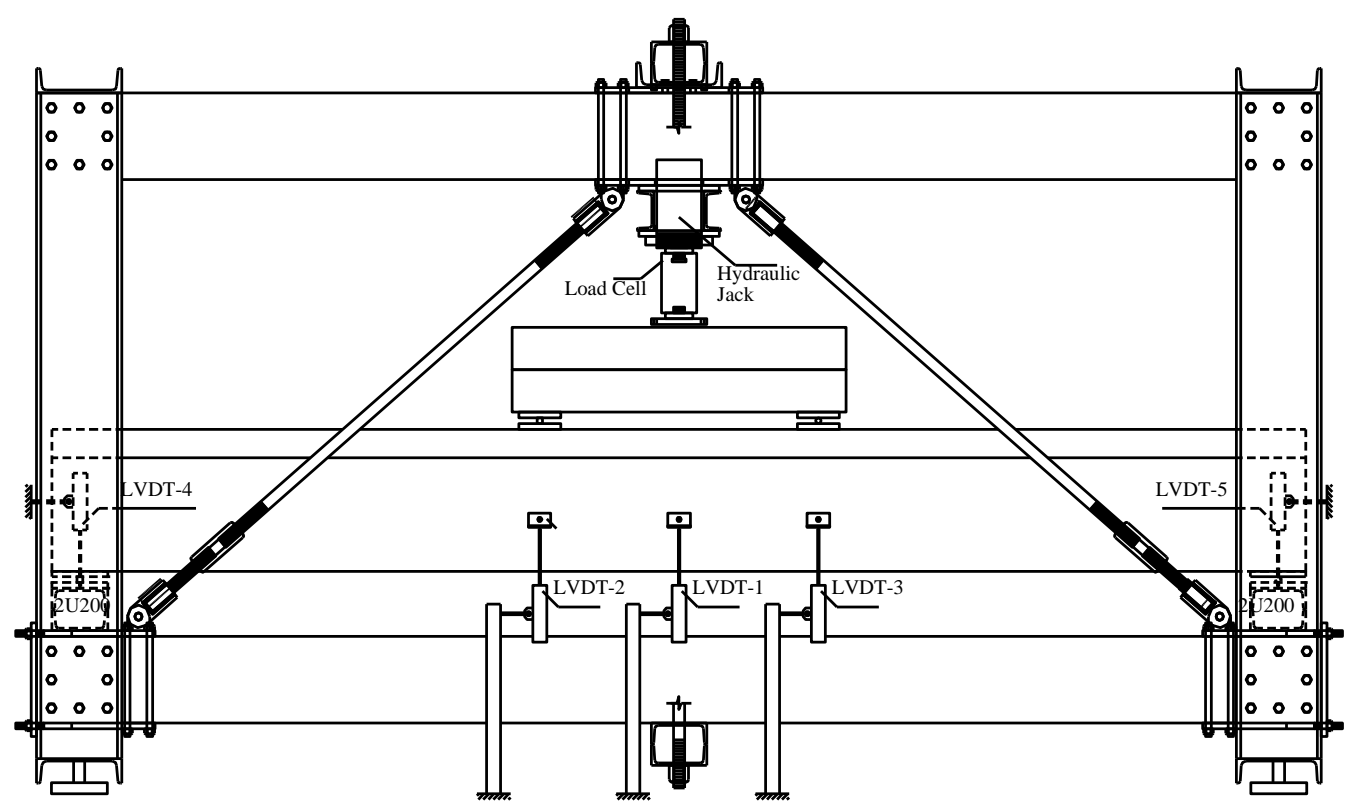

The strengthened specimens can be seen to have significantly greater ultimate load and energy absorption capacity values compared to the reference unstrengthened specimen (Figure 4). The yielding load ratios of the strengthened specimens were in the range of 2.30-2.70 times that of the reference specimen (Table 2), implying the significant contribution of the strengthening method to the load capacity. The ductilities of the strengthened specimens were about 20-50\% smaller than the ductility of the reference specimen. This limited decrease shows that this method does not result in the brittle failure of a strengthened beam and allows the beam to preserve a significant portion of its ductility.

Table 2. Test Results

\begin{tabular}{|c|c|c|c|c|c|c|}
\hline \multirow{3}{*}{ Beam } & \multirow{3}{*}{$\begin{array}{l}\text { Duct. } \\
\text { Ratio }\end{array}$} & \multicolumn{3}{|c|}{ Yielding Load (kN) } & \multirow{3}{*}{$\begin{array}{c}\text { Calculated/Test } \\
\text { Yield Load } \\
\text { Ratio }\end{array}$} & \multirow{3}{*}{$\begin{array}{c}\text { Ultimate } \\
\text { Load }(k N)\end{array}$} \\
\hline & & \multirow{2}{*}{ Cal. } & \multicolumn{2}{|c|}{ Test } & & \\
\hline & & & Absolute & Relative & & \\
\hline $\mathbf{R B}$ & $>20$ & 117 & 117 & 1.00 & 1.00 & 135 \\
\hline S1 & 10 & 298 & 293 & 2.50 & 0.98 & 310 \\
\hline S2 & $>14$ & 335 & 272 & 2.32 & 0.81 & 350 \\
\hline S3 & $>16$ & 335 & 309 & 2.64 & 0.92 & 350 \\
\hline
\end{tabular}


Figure 4. Load-Deflection Curves of the Specimens

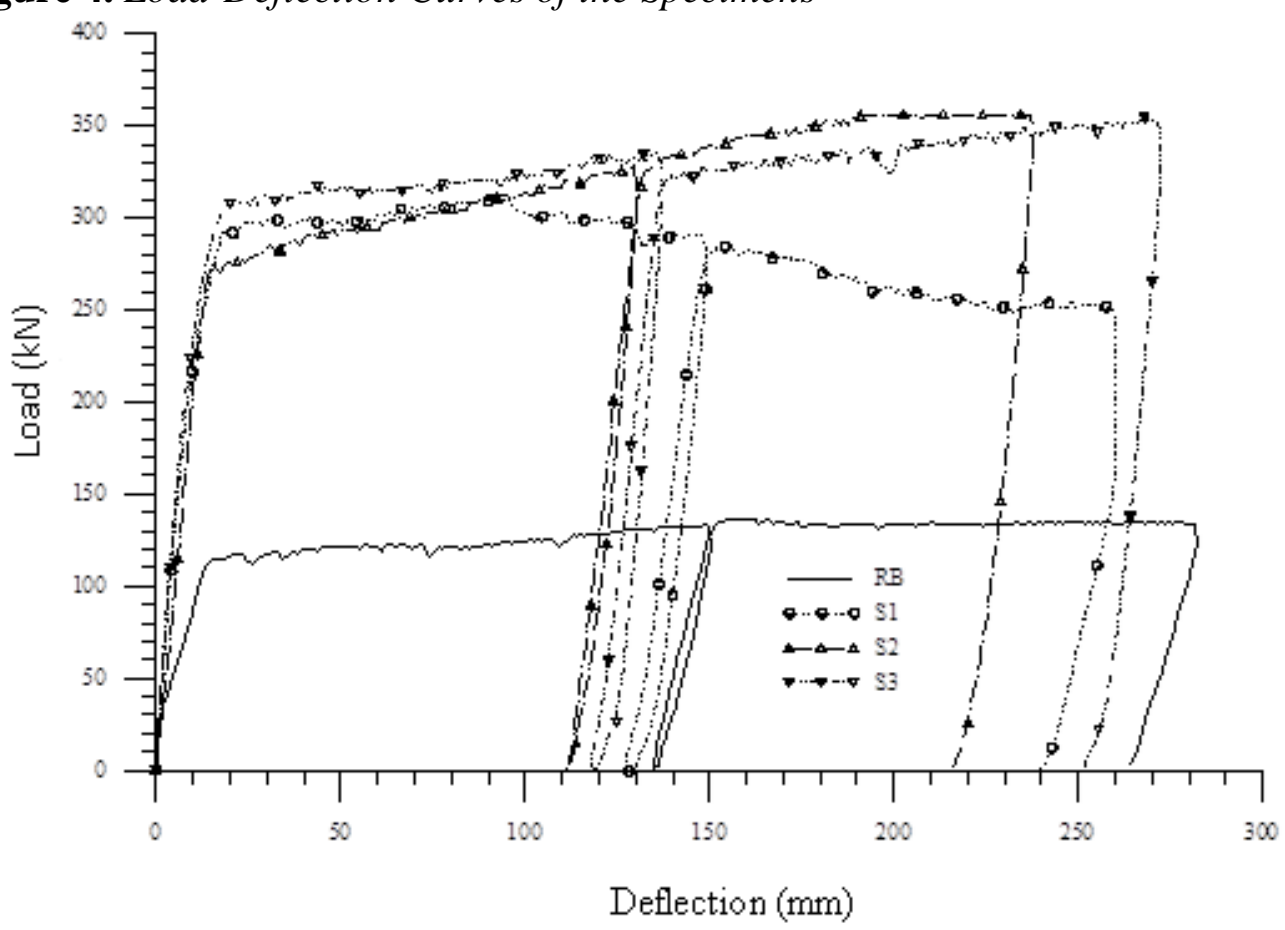

The test results indicate that the compression plates in specimens S2 and S3 contributed to the ductility of the strengthened beam, while having little influence on the load capacity. The yielding and ultimate load values of the beams S2 and S3, which were strengthened with a compression plate as well as a soffit plate, remained below or slightly exceeded the respective values of the beam $\mathrm{S} 1$, which had no compression plate (Table 2).

Different from specimen S2, the external plates were glued to the beam with the help of epoxy in specimen S3. Table 2 indicates that the epoxy-bonding of the plates contributed to the yielding load of the strengthened beam considerably (an increase of $30 \%$ ), while the ultimate load and ductility ratio values of the strengthened beam were slightly affected by epoxy-bonding. According to Figure 4 , the rigidity of the beam in the elastic range of loading and the load-deflection behavior were also influenced by the presence of epoxy to a minor extent. In specimen S2, the soffit plate yielded earlier, but the load capacity of the beam continued increasing after yielding and the strengthened beam exhibited arch behavior with a bottom tie rod. After excessive deformations, the load capacity of $\mathrm{S} 2$ increased to the level of S3 and a ductile flexural behavior was attained.

Generally, the yielding load values calculated according to the equivalent rectangular stress block analysis are in good agreement with the experimental results. The only exception for this conclusion is the yielding load value of specimen S2, which yielded significantly below its calculated value (Table 2) due to the lack of epoxy-bonding between the external plates and the beam. 


\section{Conclusions}

An easy-to-apply and convenient end connection detail for externally-plated $\mathrm{RC}$ beams, developed through a series tests, was investigated in the present study. The test results of plated RC beams, strengthened with this connection detail, were compared to the test results of a monolithic $\mathrm{RC}$ beam with identical dimensions. The influence of the use of a compression plate in addition to the tension plate and the epoxy-bonding of the external plate on the plated beam behavior was investigated in the present tests. The yielding load values of the specimens were also compared to the analytical values calculated from equivalent rectangular stress block analysis. The following conclusions were drawn:

- The external plates with the end connection detail presented in this paper increased the yielding loads of the plated beams in the range of 150-170\% and the ultimate loads in the range of 130-160\%. Furthermore, the strengthening plates resulted in limited decrease in the ductility of the plated beams, while increasing the modulus of toughness values.

- The side plates at the ends of the soffit plate prevented premature failure of the plated beams at the plate curtailment locations. All of the specimens reached yielding load values close to the calculated values, with the exception of specimen S2. Accordingly, the lack of epoxy-bonding of the external plates caused the plated beam to yield earlier before reaching its full yielding load.

- If the external soffit plate is not epoxied to the beam, the separation of the plate from the beam causes the beam to behave as a tied arch rather than a composite body. Despite the tied arch behavior, plated beams without epoxy-bonding attain the ultimate load capacities of identical composite beams (with epoxy) after excessive deformations. The ductile behavior of the plated beams with no epoxy-bonding indicates that the use of end side plates will provide adequate improvement in the beam behavior when epoxy cannot be used for reasons, such as fire risk, economy, and lack of skilled labor.

\section{References}

Ali, M. S. M., Oehlers, D. J. and Park, S. M. 2001. Comparision Between FRP and Steel Plating of Reinforced Concrete Beams. Composites, Vol.32, No.9, 1319-1328.

Anania, L., Badala, A. and Failla, G. 2005. Increasing The Flexural Performance of RC Beams Strengthened with CFRP Materials. Construction and Building Materials, Vol.19, No.1, 55-61.

Arslan, M. 1991. Strengthening of R.C. Beams by Steel Plates Bonded with Epoxy. M.Sc. Thesis. Gazi University Institute of Science.

Ashour, A. F., El-Refaie, S. A. and Garrity S. W. 2004. Flexural Strengthening of $R C$ Continuous Beams Using CFRP Laminates. Cement and Concrete Composites, Vol.26, No.7, 765-775. 
Aykac, S. 2001. Earthquake Behaviour of Repaired/Strengthened R.C. Beams. Ph.D. Thesis. Gazi University Institute of Science.

Bank, L. C. and Arora, D. 2007. Analysis of RC Beams Strengthened with Mechanically Fastened FRP (MF-FRP) Strips. Composite Structures, Vol.79, No.2, 180-191.

Gülenler, C. 1977. Strengthening of R.C. Members by Steel Plates bonded with Polymer Adhesive. M.Sc. Thesis. Istanbul Technical University.

Karahan, S. 2008. Strengthening of Reinforced Concrete Beams by Steel Plates. M.Sc. Thesis. Gazi University Institute of Science.

Kayar, S. 2008. Rehabilitation of Repaired/Strengthened R. C. Beams. M.Sc. Thesis. Gazi University Institute of Science.

Li, L., Guo, Y., Liu, F. and Bungey, J. H. 2006. An Experimental and Numerical Study of The Effect of Thickness and Length of CFRP on Performance of Repaired Reinforced Concrete Beams. Construction and Building Materials, Vol.20, No.10, 901-909.

Li, L. J., Guo, Y. C. and Liu, F., Bungey, J. H. 2008. Test Analysis for FRC Beams Strengthened with Externally Bonded FRP Sheets. Construction and Building Materials, Vol.22, No.2, 315-323.

Moon, D., Sim, J. and Oh, H. 2007. Detailing Considerations on RC Beams Strengthened with CFRP Bars Embedded in Mortar Overlay. Construction and Building Materials, Vol. 21, No.2, 1636-1646.

Mukherjee, A. and Rai, L. G. 2009. Performance of Reinforced Concrete Beams Externally Prestressed with Fiber Composites. Construction and Building Materials, Vol.23, No.2, 822-828.

Raoof, M., El-Rimawi, J. A. and Hassanen, M. A. H. 2000. Theoretical and Experimental Study on Externally Plated R.C. Beams. Engineering Structures, Vol.22, No.1, 85101.

Su, R. K. L. and Zhu, Y. 2005. Experimental and Numerical Studies of External Steel Plate Strengthened Reinforced Concrete Coupling Beams. Engineering Structures, Vol.27, No.10, 1537-1550.

Tankut, T. and Arslan, M. 1992. Behaviour of R.C. Beams Strengthened by Epoxy Steel Plate. IMO Technical Journal, Vol.3, No.4, 575-584.

Toutanji, H., Zhao, L. and Zhang, Y. 2006. Flexural Behaviour of Reinforced Concrete Beams Externally Strengthened with CFRP Sheets Bonded with an Inorganic Matrix. Engineering Structures, Vol.28, No.4, 557-566.

TS 500. 2000. Requirements for design and construction of reinforced concrete structures. Turkish Standards Institute, Turkey.

Uysal, A. 2006. Strengthening of Reinforced Concrete Beams by Epoxy Glued Steel Plates. M.Sc. Thesis. Gazi University Institute of Science.

Yang, D., Park S. and Neale, W. K. 2009. Flexural Behaviour of Reinforced Concrete Beams Strengthened with Prestressed Carbon Composites. Composite Structures, Vol.88, No.4, 497-508. 